\title{
What influences the timing of the introduction of solid food to infants?
}

\author{
Elizabeth M. Alder ${ }^{1,2}$, Fiona L. R. Williams ${ }^{2}$, Annie S. Anderson ${ }^{3}$, Stewart Forsyth ${ }^{4}$, \\ Charles du V. Florey ${ }^{2}$ and Patricia van der Velde ${ }^{2,5}$ \\ ${ }^{1}$ Faculty of Health and Life Sciences, Napier University, 74 Canaan Lane, Edinburgh EH9 2TB, UK \\ ${ }^{2}$ Section of Public Health, Division of Community Health Sciences, University of Dundee, Kirsty Semple Way, \\ Dundee DD2 4BF, UK \\ ${ }^{3}$ Centre for Public Health Nutrition Research, University of Dundee, Dundee, UK \\ ${ }^{4}$ Tayside Institute for Child Health, Ninewells Hospital and Medical School, University of Dundee, Dundee, UK \\ ${ }^{5}$ Institute for the Study of Children, Families and Social Issues, Birkbeck College, University of London, London, UK
}

(Received 12 December 2003 - Revised 5 April 2004 - Accepted 4 May 2004)

\begin{abstract}
The aim of the present study was to assess the factors which may influence the timing of the introduction of solid food to infants. The design was a prospective cohort study by interview and postal questionnaire. Primiparous women ( $n$ 541) aged between 16 and 40 years were approached in the Forth Park Maternity Hospital, Fife, Scotland. Of these, 526 women agreed to participate and seventyeight were used as subjects in the pilot study. At 12 weeks we interviewed 338 women of the study sample. The postal questionnaire was returned by 286 of 448 volunteers. At 12 weeks 133 of 338 mothers said that they had introduced solids. Those that said that they had introduced solids early $(<12$ weeks) were compared with those who had introduced solids late ( $>12$ weeks) by bivariate and multiple regression analysis. Psychosocial factors influencing the decision were measured with the main outcome measure being the time of introduction of solid food. The early introduction of solids was found to be associated with: the opinions of the infant's maternal grandmother; living in a deprived area; personal disagreement with the advice to wait until the baby was 4 months; lack of encouragement from friends to wait until the baby was 4 months; being in receipt of free samples of manufactured food. Answers to open-ended questions indicated that the early introduction appeared to be influenced by the mothers' perceptions of the baby's needs. Some of the factors influencing a woman's decision to introduce solids are amenable to change, and these could be targeted in educational interventions.
\end{abstract}

Infant diets: Solid foods: Weaning: Health promotion: Breast-feeding

Nutrition in the early years of life is a major determinant of growth and development (Fall et al. 1992). In the first Dundee infant feeding study we found that breast-feeding gave protection against gastroenteritis and respiratory infection (Howie et al. 1990), and in a follow-up study, that breast-feeding leads to less-frequent respiratory infection and lower blood pressure at age $7-8$ years (Wilson et al. 1998). The timing of the first introduction of solids was an important confounding factor for subsequent health. Infants introduced to solid food before 4 months had higher levels of morphometric features characteristic of cardiovascular risk such as increased body fat and BMI, and had more wheezy respiratory illness. The Committee on Medical Aspects of Food in its Report of the Working Group on the Weaning Diet (Department of Health and Social Security, 1994) recommends that the majority of infants should not be given solid food before the age of 4 months, and recently the World Heath Organization (2002) recommended exclusive breast-feeding until 6 months. Delaying the introduction of solid food until after 4 months may confer benefit in families with a history of atopy or gluten enteropathy (Kelly et al. 1989).

Government surveys of infant feeding found that, in Scotland, $64 \%$ of mothers had introduced solids by 3 months in 1995 (Foster et al. 1997). In 2000 this had fallen to $28 \%$, and $50 \%$ had given solid food before 4 months (Hamlyn et al. 2001). Bottle-feeding, higher birth weight, lower age of mother leaving full-time education, lower social class of husband or partner, lower educational level and maternal smoking habits were associated with earlier introduction of solid food (Hamlyn et al. 2001). The infant-feeding surveys did not ask about reasons for the timing of introduction of solids, which could be influenced by several psychosocial variables. A qualitative study found that erratic meal patterns were given as a reason for the introduction of solids by bottle-feeding women but by fewer breast-feeding women. Bottle-feeding women identify vigour of sucking as a reason for believing the infant to be hungry whereas breast-feeding women cite the change in frequency or demand for feeds at particular

\footnotetext{
Abbreviation: OR, odds ratio.

* Corresponding author: Professor Beth Alder, fax +44 131445 2627, email e.m.alder@napier.ac.uk
} 
times of the day as a reason (Wright, 1981). Bottle-fed infants sleep through the night at an earlier age than breast-fed infants and this may be an incentive to change the method of feeding (Wright, 1981; Drewett et al. 1998). In the first 6 months women may be very fatigued (Alder, 1994) and may wish to reduce the number of night feeds in order to get a longer time to sleep (Wright, 1981).

In a qualitative study, twenty-nine primiparous women recruited from Forth Park Hospital, Kirkcaldy with infants whose ages ranged from 8 to 18 weeks participated in focus groups. They were from the same population as the survey study reported in the present paper. We found that physical characteristics and the perceived hunger of the infant were the key influences on the introduction of solids (Anderson et al. 2001). For instance, physical characteristics such as the age of the infant, whether the infant was teething, and the infant reaching a certain weight or size were cited as prompts to introduce solid food. The overriding aim of all women was to settle their infant so that the child was happier and more contented.

If parents are to be encouraged to delay the introduction of solids until 4 months it is important to know their reasons for introducing solids earlier. More support from professionals has been advocated, but awareness of recommended weaning practices among some health professionals may be relatively poor (Higginson, 2001). The results from the present study would enable health professionals to focus their advice effectively. We report in the present paper the results from a study in which we aimed to explore the social and psychological reasons for introducing solids by comparing women who introduce solids early with those delaying the introduction of solids.

\section{Methods}

A consecutive sample of primiparae delivering in Forth Park Hospital, Fife, Scotland was recruited. To be eligible, women had to understand English and deliver a healthy, full-term baby of $2500 \mathrm{~g}$ or more. Women with a mental disability or under 16 years were excluded. Two women with twins were excluded. Women were recruited (between May 1999 and November 1999) in the postnatal ward, followed up with a home interview at 12 weeks postpartum, and sent a postal questionnaire at 20 weeks postpartum. Ethical approval was obtained from Fife local research ethics committee.

We chose 12 weeks because Government statistics suggest that most women would have introduced solids by the recommended time of 4 months. A difference of $50 \%$ of one standard deviation on a scale of self-efficacy (generalised self-efficacy scale; Schwarzer, 1993) (mean 29.28 (SD 4.6)) with a power of $95 \%, \alpha=0.01$, requires a sample size of 297 (Ford et al. 1995). This was used because the study tested the Theory of Planned Behaviour's ability to predict the timing of the introduction of solids. The Theory of Planned Behaviour is widely used to predict health behaviour, and self-efficacy is an essential component. This will be published elsewhere. A sample of 360 would allow the analysis of categorical data based on likely differences (for example, $70 \%$ breast- and $30 \%$ bottle-feeding) with a power of $95 \%, \alpha=0.01$, which would give us a definitive answer. We aimed to recruit 500 women over 5 months, which allowed for a dropout of $20 \%$.

Four midwives were specifically trained to carry out the home interviews and they were audited throughout the study to ensure consistency. They collected data on demographic details, parental characteristics and infant characteristics. The postcode address was used to determine a deprivation category score (Carstairs \& Morris, 1991), a measure of the woman's deprivation status. A high deprivation category of 1 score denotes affluence; 7, deprivation. The postal questionnaire sent out at 20 weeks postpartum asked about feeding type and patterns. All data were entered and verified using Epi-Info (Dean et al. 1990).

Multiple forward stepwise logistic regression was performed using SPSS for Windows (version 7.5). Because over 400 variables were generated during the interviews and through the postal questionnaire, an exploratory analysis was carried out. Using the results from the focus groups, from the search of published literature, and from the bivariate analyses, explanatory variables were grouped into six categories and logistic regression analysis performed with each group of variables. Significant variables from the first group's analysis were added to the explanatory list of the second group's analysis, and so on. This is similar to the block approach used by SPSS. The last run used the significant explanatory variables from all of the previous runs.

Because of the relatively small sample size involved in the analysis, most variables used in the regression analyses were subsumed to three levels. This was done to reduce the number of explanatory variables with response categories with small numbers of observations. This was achieved in as logical a way as possible. For example, the seven-point scale of experience of feeding a child was reduced to 'good' for the upper three points, 'neither good nor bad' for the middle point, and 'poor' for the remaining three.

The first run of the logistic regression model incorporated the key variables that were identified either at some point during the bivariate analysis, or through the focus groups. Subsequent exploratory runs used the same variables as the first run but also evaluated the impact of the health behaviour characteristics that were measured by the subjective norm scale, perceived behaviour control, attitude score and self-efficacy score. These variables were entered singly into the regression model. A final regression model tested all of the significant explanatory variables that were identified during the exploratory analysis.

The importance of each explanatory variable, adjusted for the others in its group, was assessed by the Wald $\chi^{2}$ and the odds ratios (OR) with $95 \%$ CI.

\section{Results}

Of the 541 women approached in the postnatal ward, fifteen women refused and 526 agreed to participate. Seventy-eight women were used to pilot the interviews and postal questionnaires. Of the 448 mothers invited to 
be interviewed at 12 weeks postpartum, 338 agreed $(76 \%)$. None who refused the interview was sent a postal questionnaire. The postal questionnaire was returned by 286 of the 448 women. If data were missing at 12 or 20 weeks they were excluded from the comparative analysis.

\section{Characteristics of the sample}

The women interviewed at 12 weeks were no different in their deprivation scores based on postcode, sex of baby or babies' birth weight from those not agreeing to be interviewed. However, $59 \%$ of mothers who agreed to take part were aged over 25 years compared with $33 \%$ of those who declined $\left(\chi^{2} 3 \cdot 9\right.$, df $\left.1 ; P=0 \cdot 05\right)$.

About one half of the babies were male $(n 168)$ and one half female ( $n$ 170). The mean gestation was 40.12 (SD 1.33, range 35-42) weeks. The majority of women were of white ethnic group (99\%). The majority $(66 \%)$ were married or living with a partner. The mean parental age of leaving school was 17.39 (SD 2.15) years. Only seventy-five $(16 \%)$ mothers reported that they had had health problems after the birth, including eight with mastitis and six with postnatal depression. The majority of women lived in areas with deprivation category scores of 3 or 4 (Table 1).

\section{Patterns of infant feeding}

Most women $(71 \%)$ had breast-fed their infants at least once after delivery, but by 3 months most $(86 \%)$ had also given their infants formula milk. Only $15 \%$ breastfed exclusively for 12 weeks. At the 12-week interview $40 \%$ said that they had introduced solids (133/338) although forty-three of these said that they had stopped and started. When asked at 12 weeks when they intended to give their infant solid food, most $(60 \%)$ said at 16 weeks, but twenty-three $(11 \%)$ said when their infants were ready. Seven mothers had not thought about when they might introduce solids. In the postal questionnaire follow-up at 20 weeks, 272 of the 286 respondents $(95 \%)$ had given their babies solids, and in total 278 reported the age at which solids were introduced (Fig. 1).

Comparison of early ( $\leq 12$ weeks) and delayed $(>12$ weeks) solids

The bivariate analysis revealed that women who introduced their infants to solids early were more likely to have a male baby (OR 2.01; $95 \%$ CI 1.26, 3.21), to use formula feed

Table 1. Deprivation index (Carstairs \& Morris, 1991) of the sample interviewed at 12 weeks

\begin{tabular}{lrc}
\hline Deprivation category score & $n$ & Percentage of 336 \\
\hline 1 (Affluent) & 15 & $4 \cdot 5$ \\
2 & 18 & $5 \cdot 4$ \\
3 & 157 & $46 \cdot 7$ \\
4 & 121 & $36 \cdot 0$ \\
5 & 21 & $6 \cdot 3$ \\
6 & 4 & $1 \cdot 2$ \\
7 (Deprived) & 0 & \\
Missing & 2 & \\
Total & 338 & \\
\hline
\end{tabular}

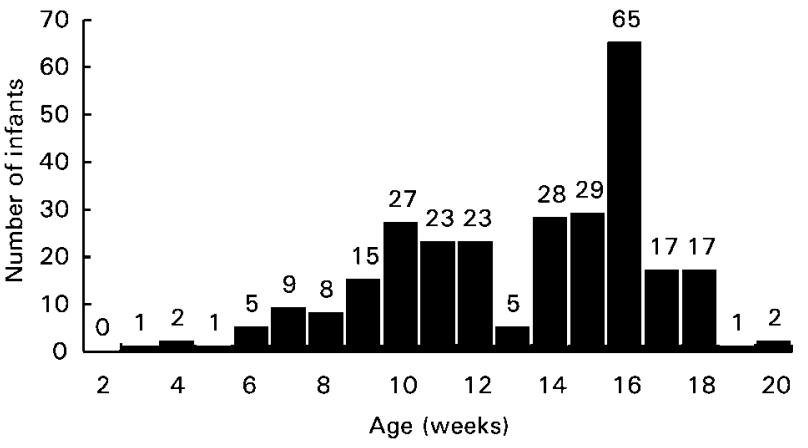

Fig. 1. Distribution of age at which solids introduced (combined from data from 12-week interview and 20-week postal questionnaire; $n$ 278).

(OR 2.10; $95 \%$ CI 1.27, 3.47), and to have received free food samples (OR 2.74; $95 \%$ CI 1.70, 4.43). The women were more likely to have smoked during pregnancy (OR $3.27 ; 95 \%$ CI 1.90, 5.60), to be from a lower social class

Table 2. The dependent and independent variables used in the exploratory (last model) and final multiple logistic regression models

Dependent variable

Whether infant was introduced to solids $\leq 12$ or $>12$ weeks Independent variables

Last exploratory model

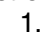

2.

3.

4.

6.

7.

8.

10.

Final model

$1 . \quad$ Woman's age

2.

3.

7.

Woman's age

Woman's age when left full-time education

Knowledge about why the guidelines recommend 4 months

Anxiety about introducing the infant to solid food

Belief that giving solids early ( $<4$ months) might harm the infant*

Agreement with waiting until 4 months before giving solids*

Own mother's opinion*

Deprivation score*

In receipt of free sample*

Infant's sex

Agreement with waiting until 4 months before giving solids

Own mother's opinion*

Deprivation score*

Woman employed before pregnancy

Looking forward to giving solids for the first time

Belief that giving solids early ( $<4$ months) might harm the infant

Giving the infant solid food $<4$ months, means that the infant had reached a milestone early

9.

Agreement that waiting until 4 months was correct advice*

10.

months was correct ad
Friends say wait until 4 months *

People who are important to me say wait until 4

months

In receipt of free sample*

\footnotetext{
* Significant variables $(P<0.05)$ in the regression model.
} 
Table 3. Multiple regression analysis for the final model (see Table 2); the dependent variable was whether the infant was introduced to solids $\leq 12$ or $>12$ weeks $(n 213)^{\star}$

\begin{tabular}{|c|c|c|c|c|c|c|c|}
\hline Variable & $n \dagger$ & Percentage of total & Wald $\chi^{2}$ & $\mathrm{df}$ & $P$ value & Odds ratio & $95 \% \mathrm{Cl}$ \\
\hline Opinions of baby's maternal grandmother & & & $17 \cdot 10$ & 1 & $<0.001$ & 0.94 & $0.91,0.97$ \\
\hline Deprivation score & & & $10 \cdot 57$ & 3 & 0.014 & & \\
\hline Score $1+2 \ddagger$ & 17 & 8 & & & & $1 \cdot 0$ & \\
\hline Score 3 & 95 & 45 & 1.88 & 1 & 0.170 & 0.28 & $0.46,1.72$ \\
\hline Score 4 & 84 & 39 & $3 \cdot 89$ & 1 & 0.048 & 0.16 & $0.25,0.99$ \\
\hline Score $5+6$ & 17 & 8 & 8.07 & 1 & 0.004 & 0.04 & $0.01,0.36$ \\
\hline $\begin{array}{l}\text { Belief that the recommendation to delay } \\
\text { giving solids until the baby is } \\
4 \text { months is correct }\end{array}$ & & & 9.09 & 2 & 0.011 & & \\
\hline Agreeł & 100 & 47 & & & & 1.0 & \\
\hline No opinion either way & 20 & 9 & $5 \cdot 82$ & 1 & 0.016 & 0.21 & $0.06,0.75$ \\
\hline Disagree & 93 & 44 & $6 \cdot 41$ & 1 & 0.011 & 0.35 & $0.16,0.79$ \\
\hline $\begin{array}{l}\text { Closest friends recommend waiting until the } \\
\text { baby is } 4 \text { months before giving solids }\end{array}$ & & & $9 \cdot 22$ & 2 & 0.010 & & \\
\hline Agreeł & 48 & 23 & & & & 1.0 & \\
\hline No opinion either way & 37 & 17 & 6.09 & 1 & 0.014 & 0.14 & $0.03,0.67$ \\
\hline Disagree & 128 & 60 & $9 \cdot 22$ & 1 & 0.002 & $0 \cdot 11$ & $0.03,0.45$ \\
\hline In receipt of free sample of solid food & & & $14 \cdot 19$ & 1 & 0.001 & $4 \cdot 38$ & $2.03,9.45$ \\
\hline
\end{tabular}

* We selected to run the model forwards and thus the categories were compared with the first variable, the deprivation score.

† Numbers included in multiple regression analysis.

$\ddagger$ Reference group

(OR 2.12; $95 \%$ CI 1.28, 3.52), and to have left full-time education before 18 years (OR 2.74; $95 \%$ CI 1.42, 5·37). Younger women (under 20 years) were also more likely to introduce solids early (OR 2.5; $95 \%$ CI 1.21, 5.2).

Women who introduced solids early did not differ from those who delayed introducing solids in the following respects: living in extended families; marital status; employment status of women or partner at 12 weeks; health problems after the birth; age of mother; gestation age of infant.

Women who had already introduced solids by 12 weeks were asked about their decision. Many (ninety-six; 56\%) hoped that their infant would settle more easily after the introduction of solids and many (eighty-eight; 52\%) hoped that the infant would sleep through the night. Women said that they continued to give solids because the infant seemed to enjoy them $(141 ; 83 \%)$ and that the infant was happier and more content $(102 ; 60 \%)$. Most women $(128 ; 75 \%)$ were unconcerned about introducing solids at the time that they did.

\section{Regression results}

At the end of the exploratory regression analyses, seven variables contributed significantly $(P<0.05)$ and persistently to whether a woman introduced her infant to solids before or after 12 weeks of age (Table 2). Women were more likely to introduce their infants to solids early if they had delivered a boy and if they were young (under 20 years). Women who disagreed with advice to wait until their infant was 4 months old before introducing solids, with high deprivation scores, who had received free samples of manufactured food, who did not believe that giving solids early would harm their infant, and who were strongly influenced by their own mothers' opinion were more likely to introduce solids early (Table 3 ).

\section{Discussion}

We chose to analyse the data using 12 weeks because of our expectation, which proved accurate, that most mothers would have introduced solids by 16 weeks. Of the mothers, $87 \%$ had introduced solids by 16 weeks inclusive.

The percentage introducing solids by 12 weeks inclusive $(41 \%)$ was higher than the data reported for Scotland $(28 \%)$ in the 2000 feeding survey (Hamlyn et al. 2001).

At 20 weeks, nearly all women $(95 \%)$ had given their babies solid food. Bivariate analysis showed that the early introduction of solids was associated with young age, having a male baby, social class, age of leaving fulltime education and smoking. In the regression, only deprivation was an independent factor. In a New Zealand study of over 1800 infants, low levels of maternal education and maternal smoking were found to be most strongly associated with the early introduction of solids (Ford et al. 1995) and socio-economic status and education were reported in the 2000 survey (Hamlyn et al. 2001). None of these variables is open to change by a direct intervention on infant feeding, and are similar to those that are associated with the duration of breast-feeding. The regression analysis also showed that the opinions of the baby's maternal grandmother and of friends were significant, suggesting the importance of the social group. These and the mothers' beliefs about the correctness of the advice may be open to change.

The timing of when the mother is given the free sample may be crucial. If it comes before 4 months perhaps she is encouraged to try the food and it may imply that it is acceptable to give solids before 4 months. Future research would need to clarify whether it was the timing of being given the food sample or whether it was simply being given free samples that caused the association. 
Bottle-feeders introduced solids earlier than breastfeeders but this difference disappeared in the regression analysis, probably because it was confounded with deprivation. Those who had not yet introduced solids at 12 weeks hoped that the baby would settle more easily and sleep though the night after solids were introduced. The baby being happier, more content and seeming to enjoy solids were reasons for continuing solids once started. These findings supported the results from the qualitative study (Anderson et al. 2001).

The data were mainly collected at 12 weeks by home interview, at which time $40 \%$ of mothers had already introduced solids. The women's reasons were therefore assessed after they had introduced solids and therefore were retrospective. It would be interesting to assess the decision making immediately before the introduction of solids and this would need to be assessed using daily diaries.

Successful interventions need to focus on those variables that can be changed by health promotion interventions whilst recognising the need for greater societal changes. Both the qualitative and quantitative results support the suggestion that the mothers' introduction of solids is led by their perception of their baby's needs; this could provide a promising message for the design of an effective educational intervention.

\section{Acknowledgements}

We thank the midwife researchers, Mrs Pamela Galloway, Mrs Alison Lowrie, Mrs Linda Jones and Mrs Veronica Keyte for their careful data collection, Carol Ann Guthrie for her preliminary work on the study and Dr Tahir Mahmood, Consultant Obstetrician, Forth Park Hospital for access to participants. Professor Peter Howie, Professor of Obstetrics and Gynaecology, University of Dundee was closely involved with the design of the study and made an invaluable contribution. We are grateful for the cooperation of the staff at Forth Park Hospital for the successful recruitment rates, and to the women who participated. The work was funded by the Chief Scientist Office, Scotland (grant no. K/OPR/2/2/D535).

\section{References}

Alder B (1994) The psychobiology of mood and sex in pregnancy and the puerperium. In Female Sexuality. Psychology, Biology and Social Context, pp. 21-29 [PYL Choi and P Nicolson, editors]. New York: Harvester Wheatsheaf.

Anderson AS, Guthrie C-A, Alder B, Forsyth S, Howie PW \& Williams FLR (2001) Rattling the plate - reasons and rationales for early weaning. Health Educ Res 16, 471-479.

Carstairs V \& Morris R (1991) Health and Deprivation in Scotland. Aberdeen: University Press.

Dean J, Dean A, Busten A \& Dicker R (1990) Epi-Info Version 5. Atlanta, GA: Centres for Disease Control.

Department of Health and Social Security (1994) Weaning and the Weaning Diet Report of the Working Group on the Weaning Diet of the Committee on Medical Aspects of Food Policy. London: HM Stationery Office.

Drewett R, Wright P \& Young B (1998) From feeds to meals: the development of hunger and food intake in infants and young children. In Current Issues in Infancy and Parenthood, pp. 204-217 [CA Niven and A Walker, editors]. Oxford: Butterworth Heinemann.

Fall CHD, Barker DJ, Osmond C, Winter PD, Clark PM \& Hales CN (1992) Relation of infant feeding to adult serum cholesterol concentration and death from ischaemic heart disease. BMJ 303, 801-805.

Ford RPK, Schluter PJ \& Mitchell EA (1995) Factors associated with the age of introduction of solids into the diet of New Zealand infants. New Zealand Cot Death Study Group. J Paediatr Child Health 31, 469-472.

Foster K, Lader D \& Cheeseborough S (1997) Infant Feeding 1995. London: The Stationery Office.

Hamlyn B, Booker S, Oleinikova K \& Wands S (2001) Infant Feeding 2000. London: The Stationery Office.

Higginson C (2001) Nutrition in the Under Fives. Edinburgh: Health Education Board for Scotland.

Howie PW, Forsyth JS, Ogston SA, Clark A \& Florey CD (1990) Protective effect of breast feeding against infection. BMJ 300, $11-16$.

Kelly DA, Phillips AD, Elliott EJ, Dias JA \& Walker-Smith JA (1989) Rise and fall of coeliac disease 1960-85. Arch Dis Child 64, 1157-1160.

Schwarzer R (editor) (1993) Measurement of Perceived Self-Efficacy. Psychometric Scales for Cross-Cultural Research. Berlin, Germany: Freie Universität Berlin.

Wilson AC, Forsyth JS, Green SA, Irvine LA, Hau C \& Howie PW (1998) Relation of infant diet to childhood health: seven year follow up of cohort of children in Dundee infant feeding survey. BMJ 316, 21-25.

World Health Organization (2002) Infant and Child Nutrition: Global Strategy for Infant and Young Child Feeding, Executive Board paper no. EB 109/12. Geneva: WHO.

Wright P (1981) Development of feeding behaviour in early infancy: implications for obesity. Health Bull (Edinb) 39, 197-205. 